\title{
Developmental the pattern of embryogenic microspore of rice (Oryza sativa L.) based on morphological characteristic
}

Siti Nurbaiti, Yekti Asih Purwestri, Budi Setiadi Daryono, Endang Semiarti*, Ari Indrianto*

Department of Tropical Biology, Faculty of Biology, Universitas Gadjah Mada, Jl. Teknika Selatan, Sekip Utara, Yogyakarta 55281, Indonesia

\begin{abstract}
Microspore culture is a rapid approach to get double haploid plants in shorten time which is important for plant breeding. Microspore culture of pigmented rice cultivar Segreng was used to observe the pattern of embryogenic development based on the characteristics of morphology. Characterization between embryogenic and non-embryogenic microspores was conducted after exposed anther to carbohydrate starvation in B medium culture at $33^{\circ} \mathrm{C}$ for 4 days. The result showed that enlarged microspore and star-like structure of fragmented cytoplasm become a marker of embryogenic microspore after stresses treatment. More complex of fragmented microspore was found at 4 days in A2 medium and developed further into multicellular structure. These multicellular structures might be originated either by symmetrical or asymmetrical division. The longer incubation, the higher frequency of complex fragmented microspore that developed into multicellular structure release from exine has appeared.
\end{abstract}

Keywords: Development process, embryogenic microspore, morphological character, rice.

Received: 12 December 2019 Revised: 24 February 2020 Accepted: 1 March 2020

\section{Introduction}

Pollen formation underwent two developmental processes, namely sporogenesis producing four haploid cells and gametogenesis resulting in mature pollen grains composed of two sperm and one vegetative nucleus (Zhang et al., 2011). In contrast, by stresses application in vitro of isolated microspore or anther culture, the developmental fate can be reprogrammed into embryogenesis regenerating new haploid or doubled haploid plants (Bélanger et al., 2018). This technology is a rapid approach to homozygosity that shortens time than conventional breeding (Gueye \& Ndir, 2010). Microspore culture is not only used in providing many candidates single cells for producing doubled haploid plants but also an excellent material for molecular studies in plant developmental plasticity and cell fate decision (Seifert et al., 2016). During the shifting of developmental fate, cellular dedifferentiation and interruption of transcription and translation activities leading to pollen formation occurred (Bélanger et al., 2018).

Cell activities and structural organizations were affected as reprogramming to embryogenesis taken place (Satpute et al., 2005). Changes analysis of stress-induced embryogenic microspore involved the cytological, biochemical, and molecular levels (Obert et al., 2005; SeguíSimarro \& Nuez, 2008). The star-like morphology becomes a prominent marker related to embryogenic potential after microspore exposed to the stress that switches

\footnotetext{
* Corresponding Author:

Endang Semiarti, Ari indrianto

Department of Tropical Biology, Faculty of Biology,

Universitas Gadjah Mada, Yogyakarta, Indonesia

Phone: +6285642950817(ES) / +6285643287350(AI)

Fax: +62274580839

e-mail: endsemi@ugm.ac.id/ariindri@ugm.ac.id
}

the developmental pathway from gametophytic into sporophytic (Maraschin et al., 2005; Pauls et al., 2006; Sanchez-Diaz et al., 2013). The star-like structure has enlarged in size and the vegetative nucleus in the center cell and showed cytoplasmic strands. The re-localization of the nucleus to the center of the cell resulted from cytoskeleton rearrangement as the first effect after stress treatment (Seifert et al., 2016).

In Sanchez-Diaz et al. (2013), star-like morphology was observed on the fifth day of culture after stressed wheat anther in $0.7 \mathrm{M}$ mannitol for 5 days. Then multicellular structures inside the exine wall were observed at 10 days of culture. After 15 days of culture, this multicellular structure has been released from the exine, actively divided and formed protoderm as the first sign of differentiation. The visual assessment also used by Seifert et al. (2016) to analyze the transcriptome and small RNA data in wheat microspore embryogenesis which represents a crucial stage in the acquisition of embryogenic potential. Those stages were star-like structures from 10 days coldstress pretreatment and microspore that undergoing the first nuclear division of the vegetative nucleus in the center cell.

Barley, wheat, rapeseed, and tobacco as model species of embryogenesis microspore, have numerous comprehensive studies of microspore development including gene expression profiling, transcriptome, proteome, and ultrastructural aspects (Obert et al., 2005; Joosen et al., 2007; Malik et al., 2007; Sanchez-Diaz et al., 2013; Seifert et al., 2016; Bélanger et al., 2018). In rice, although it was among the species that have been developed and applied through doubled haploid production, a limited study exploring the entire morphological and molecular changes related to pattern formation of microspore culture in induced embryogenesis was recorded. Whole anther 
culture becomes commonly performed experiments for producing regenerated plants from callus (Premvaranon et al., 2011; Golam et al., 2014). Morphological and structural events during androgenesis of rice were described in this study to distinguish the embryogenic microspore and its further pattern development among the population of non-embryogenic microspore. The differences in cellular features were studied to characterize the sequential stages of microspore embryogenesis of rice.

\section{Methods}

\section{Donor plants and stress treatment of anthers}

In this study, the local pigmented rice cultivar Segreng from Yogyakarta was used as a donor plant. The seedlings were grown in the pot containing soil and fertilizer (3:1) under natural conditions after seeds were sown in a nursery. Panicles were collected at the booting stage before the spike emerged from leaf sheath. Cold pretreatment was applied to the panicle by incubating at $4{ }^{\circ} \mathrm{C}$ for 4-7 days.

After cold pretreatment, selected spikelet containing anthers with mid- to the late-uninucleate stage of microspore were surface-sterilized with commercial bleach (containing 5,2\% (w/v) $\mathrm{NaOCl}$ ) for 2 min and then alcohol $96 \%$ for $1 \mathrm{~min}$, followed by 2 min rinse with distilled water. Isolation of anthers from spikelet was conducted by cutting the $1 / 3$ spikelet from the basal part. About 180 anthers were plated in $4 \mathrm{ml} \mathrm{B}$ medium (Kyo \& Harada, 1986) consisting of $1490 \mathrm{mg} / \mathrm{l} \mathrm{KCl}, 110 \mathrm{mg} / \mathrm{l} \mathrm{CaCl} 2,250$ $\mathrm{mg} / \mathrm{l} \mathrm{MgSO} 4.7 \mathrm{H}_{2} \mathrm{O}, 136 \mathrm{mg} / 1 \mathrm{KH}_{2} \mathrm{PO}_{4}, 54,63 \mathrm{~g} / \mathrm{l}$ mannitol and $\mathrm{pH} 7.0$ which was filter sterilized. The cultures were incubated at $33^{\circ} \mathrm{C}$ for 4 days.

\section{Isolation of microspores and morphological analysis of embryogenic microspores}

Microspores were isolated from anther culture in B medium. Microspores that shed in B medium from the dehiscence anther and which are stirred from the remaining anther were filtered using a $40 \mu \mathrm{m}$ nylon filter, then centrifuged at $800 \mathrm{rpm}$ for $7 \mathrm{~min}$. The pellet of microspore was resuspended with $\mathrm{B}$ medium and centrifuged at $500 \mathrm{rpm}$ for $3 \mathrm{~min}$. For the final microspore culture, a 2 $\mathrm{ml} \mathrm{A} 2$ medium was used and incubated in $25^{\circ} \mathrm{C}$ for further development of stress-induced embryogenic microspores.

The morphological characteristic of microspore after 4 days of stress treatment by incubating in B medium at 33 ${ }^{\circ} \mathrm{C}$ and 4,8 , and 15 days after transferred onto A2 medium was observed under an inverted microscope. The percentage of microspore with a similar feature was counted.

\section{Results}

Stress treatment in medium B as carbohydrate starvation and incubation at $33{ }^{\circ} \mathrm{C}$ in vitro culture of anther was carried out to induce microspores embryogenesis of rice. The response of isolated microspore in the embryogenic potential acquisition was observed. After four days of stress treatments, the suspension from B medium contained a mixture of the responsive microspores which were embryogenic and unresponsive microspores or non- embryogenic. Based on morphological features, embryogenic microspores were the microspore with clear cytoplasm as in the late-uninucleate microspore or microspores with fragmented cytoplasm. These embryogenic microspores had a bigger size than the non-embryogenic microspores. In contrast, the non-embryogenic microspores were smaller in size and showed plasmolysis-like cells with thicker cell wall compared to embryogenic microspore (Fig. 1).

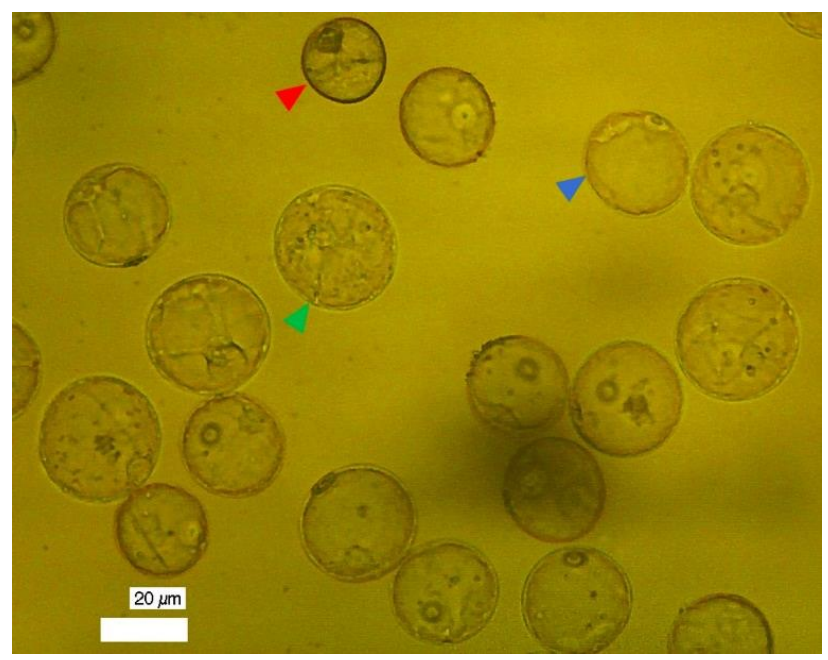

Figure 1. Shed microspore from anther culture in B medium after 4 days incubation at $33{ }^{\circ} \mathrm{C}$ showing mixture of embryogenic microspore with clear cytoplasm (blue head arrow) or fragmented star-like (green head arrow) and non-embryogenic microspore (redhead arrow)

Based on the nucleus position and the appearance of cytoplasm, there were three types of embryogenic microspores observed here. Type 1 showed no significant difference compared to late uninucleate microspore or vacuolated microspore. Unlike type 1, type 2 and type 3 started to show cytoplasm fragmentation caused by cytoskeleton rearrangements. However, type 2 and type 3 have different locations of the nucleus. The nucleus is located in the periphery cell and the center of the cell on type 2 and type 3 , respectively (Fig. 2).

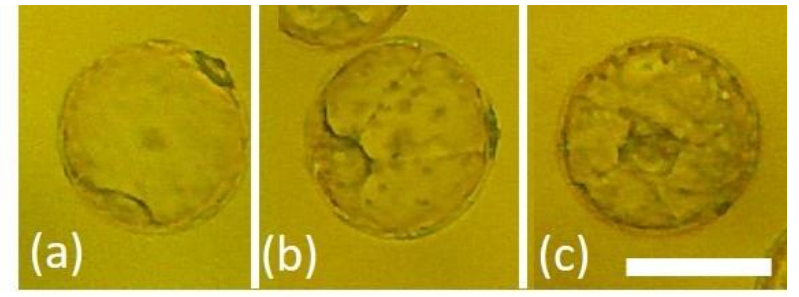

Figure 2. Types of embryogenic microspore after incubation in B medium at $33{ }^{\circ} \mathrm{C}$ for 4 days. Type 1,2 , and 3, respectively. Bar, $50 \mu \mathrm{m}$

Embryogenic microspore from stressed anthers showed further development after being transferred onto A2 medium. Variability in the level of embryogenic microspore development was found during the time of observation (Fig. 3). On the fourth day in A2 medium, microspores with more complex fragmentation of cytoplasm appeared which indicated by generating complex rearrangement of cellular inside and increasing the cytoplasmic volume. Furthermore, these microspores undergo cell 
division producing multicellular or multinuclear structures. The pathway of initial division in fragmented microspore occurred both symmetrically and asymmetrically, although it was not clearly seen whether it occurred in the vegetative or generative nucleus (Fig. 4). There was found a partition inside the cell which likely will divide the cell into two new same size cells, while another generated different cell size with smaller cell showing bulge structure. After 8 days of culture in A2 medium, not only was found the multicellular structure inside the exine, but also the multicellular structure which releases from exine producing globular-like structure.
During the onset of embryogenic microspore development (Fig. 5), the percentage of each structure was counted (Fig. 6). As the longer time of incubation, from 4 days in B medium to 8 days in A2 medium, enlarged and fragmented microspore were decrease while complex fragmented and multicellular structures have risen. Multicellular structure released from exine was higher at 15 days of incubation in A2 medium compare to 8 days in A2. This pattern indicated that the observed embryogenic microspore developed into the further stage as a longer time of culture

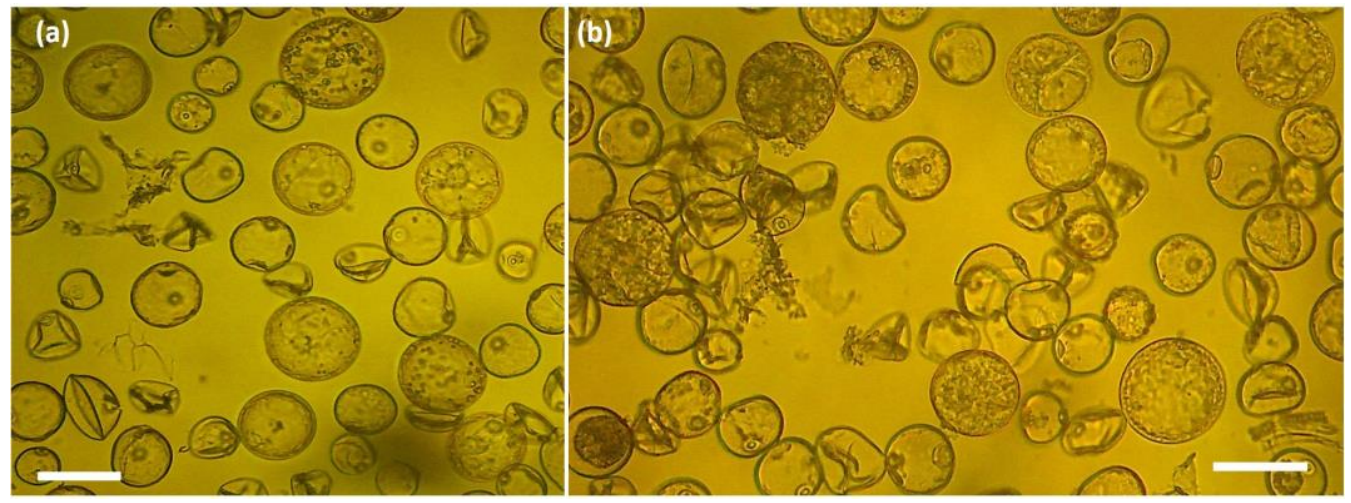

Figure 3. The population of embryogenic microspore at 4 days (a) and 8 days (b) culture in A2 medium with different levels of development. Bar, 50 $\mu \mathrm{m}$
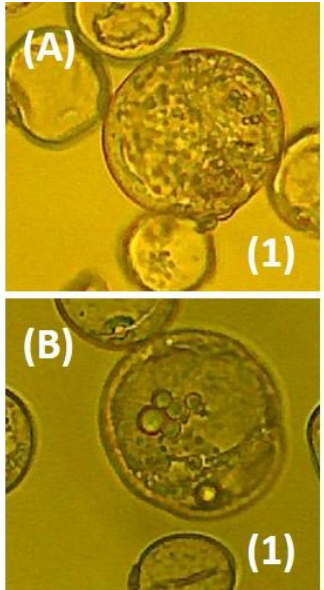
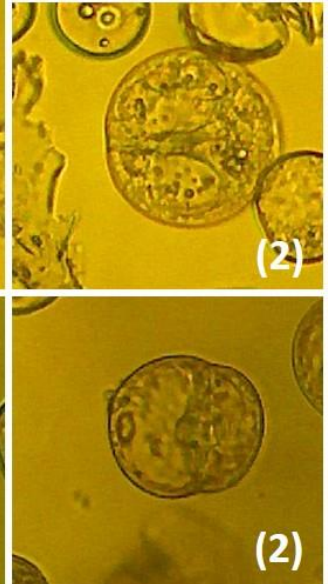
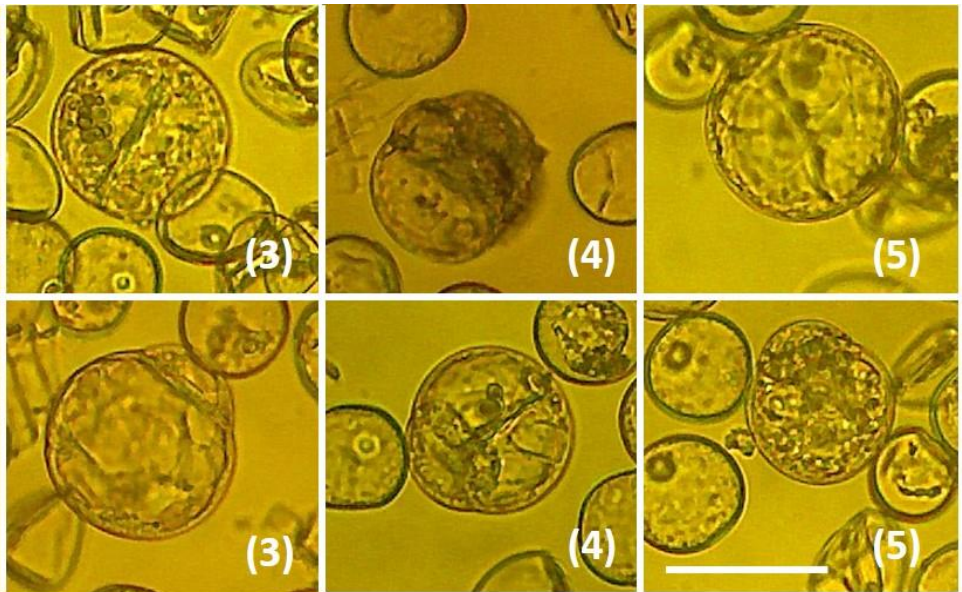

Figure 4. The pathway of embryogenic microspore cell division during further development in A2 medium. Symmetric division (A1-5) and asymmetric division (B1-5). Bar, $50 \mu \mathrm{m}$
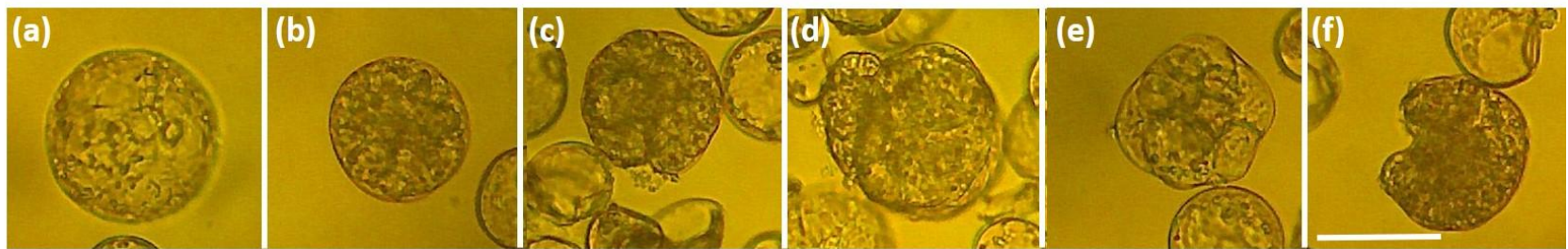

Figure 5. Development onset of embryogenic microspore of rice in A2 medium. (a) more complex fragmented microspore; (b) multicellular structure inside the exine and (c-f) multicellular structure with ruptured exine showing globular-like shape. Bar, $50 \mu \mathrm{m}$ 


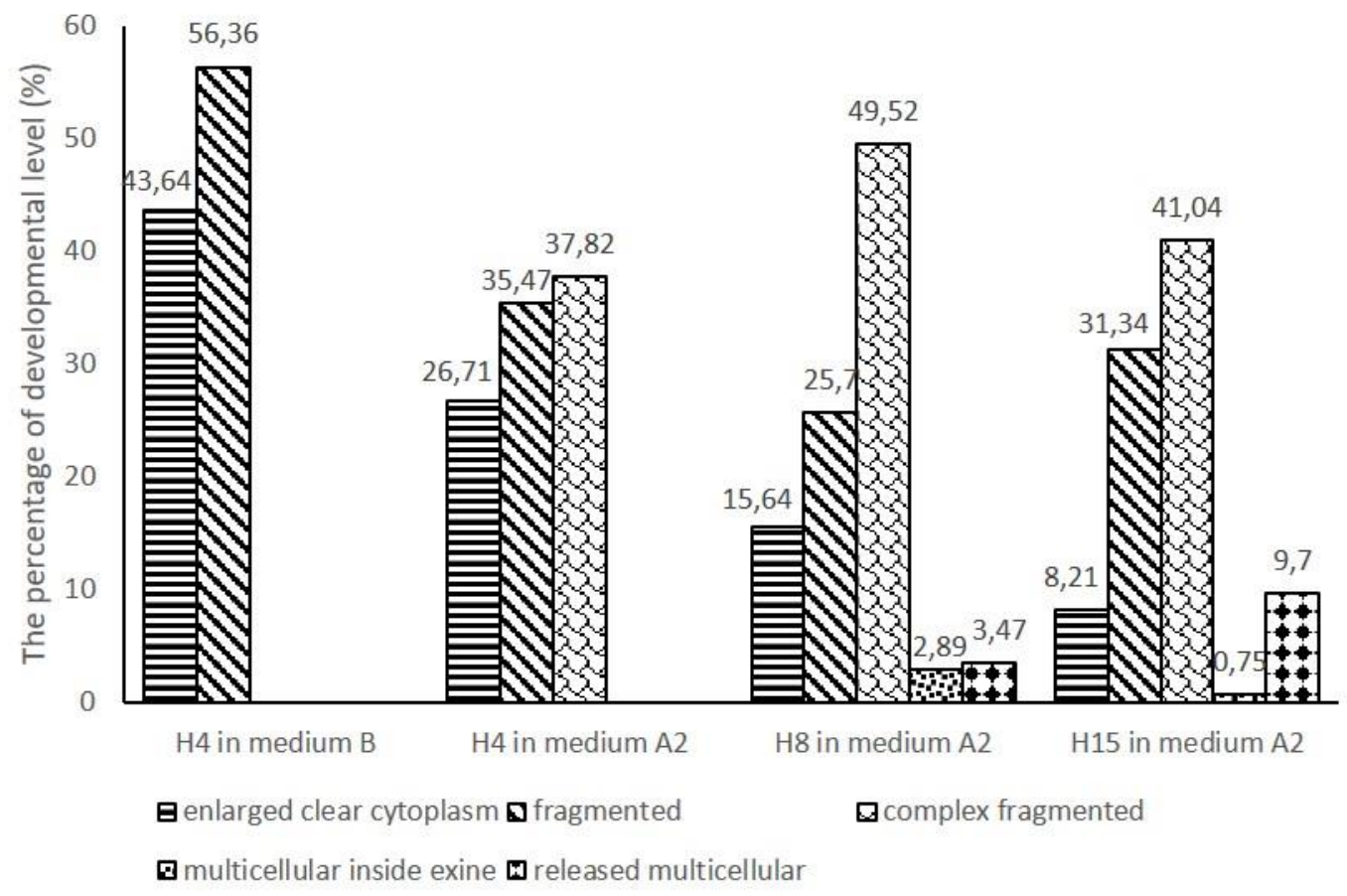

Figure 6. The percentage of each development level during rice microspore embryogenesis in sequential time of culture

\section{Discussion}

Unlike other studies in barley, rapeseed, wheat, and tobacco (Touraev et al., 1997; Indrianto et al., 2001; Maraschin et al., 2005; Satpute et al., 2005; SeguíSimarro \& Nuez, 2008; Daghma et al., 2014), investigation of embryonic development of microspore culture in rice has been rarely reported. In this study, descriptive monitoring of microspore embryogenesis was documented from the shedding period until generating a multicellular structure as a parallel developmental process.

Stress treatments given by carbohydrate starvation in B medium containing mannitol and incubation at $33^{\circ} \mathrm{C}$ for 4 days to anthers were sufficient to reprogram the developmental pathway of microspores. The responsive microspores undergo cell structural changes as marked with enlargement in size and fragmentation. Based on Indrianto et al. (2001), embryogenic microspore undergo continuous developmental process which is started from the enlarged microspore possessing similar character as late uninucleate of normal pollen development (type 1) become the star-like fragmented cytoplasm with nucleus in periphery (type 2) to the central cell (type 3) (Fig. 2).

The population of microspores both in B and A2 culture media showed a mixture of different levels of development. This phenomenon related to the variability of individual pollen developmental state. As rice has inflorescence structure, heterogeneity of pollen development in one panicle gradually differs from the basal to the top. Daghma et al. (2014) emphasized that the signal perception received by each microspore may differ as the position inside the anther was different. Therefore, the response of each microspore was dissimilar. Work by Góralski et al. (2005) in maize isolated microspore found similar results where heterogeneous structures of the different developmental stages occurred between freshly isolated microspores at day 0 of culture and multicellular structures at older of incubation time. Satpute et al. (2005) also found a mixture of various developmental in embryogenic microspore of Brassica napus L. after inductive stress treatment at $32{ }^{\circ} \mathrm{C}$ for 8 hours.

Embryogenic microspores continued its development after being transferred to A2 medium. The complex structure produced by cellular rearrangement underwent several cell divisions and generated a globular-like structure. Figure 5 showed a series of development of embryogenic microspores. Obert et al. (2005) stated that the development of a multicellular or multinuclear structure can follow two main pathways, namely symmetric and asymmetric. In the symmetric pathway, microspore directly produced two same cells without differentiation of generative and vegetative cell which was different in size. While in the asymmetric pathway, the initial division generated generative and vegetative nuclei in different sizes and one of these nuclei or both continued to divide producing multicellular or multinuclear structure. But in our sequential time of observation, the pathway of multicellular or multinuclear production was unclearly distinguishable. Nevertheless, there were found some symmetrical and asymmetrical cell structures (Fig. 5) represented symmetric and asymmetric cell proliferation.

The series of cell division caused multicellular to emerge from the exine. The structure of released multicellular from the exine wall determined the fate of development (Obert et al., 2005). If the compact structure was released, it probably developed into an embryo. In contrast, if the loose structure was released, commonly when it burst too early, the callus will be produced. The examination of these released structures from exine would become the further focus in this study together with optimi- 
zation for regenerating embryo into a double haploid plantlet.

In conclusion, the results of this study indicated that the development of embryogenic microspores in rice cultivar Segreng shows a similar pattern to early zygotic embryogenesis development as longer incubation in A2 medium. Multicellular structures that developed from starlike fragmented microspore were found in A2 medium on day 4 (at early growth stage) via symmetric and asymmetric division. Rice microspore can be used as one alternative model species to observe the development of embryogenic microspore.

\section{Acknowledgement}

This work was supported by The Directorate of Research and Community Service, Directorate General of Research and Development Strengthening, The Ministry of Research, Technology, and Higher Education, Republic of Indonesia in the scheme PMDSU research grant 2019 contract no. 2935/UN1.DITLIT/DIT-LIT/LT/2019 to $\mathrm{AI}$ as PI.

\section{References}

Bélanger, S., Marchand, S., Jacques, P. étienne, Meyers, B., \& Belzile, F. (2018). Differential expression profiling of microspores during the early stages of isolated microspore culture using the responsive barley cultivar Gobernadora. G3: Genes, Genomes, Genetics, 8(5), 1603-1614. doi:10.1534/g3.118.200208

Daghma, D. E. S., Hensel, G., Rutten, T., Melzer, M., \& Kumlehn, J. (2014). Cellular dynamics during early barley pollen embryogenesis revealed by time-lapse imaging. Frontiers in Plant Science, 5(DEC), 1-14. doi:10.3389/fpls.2014.00675

Golam, F., Zaidi, K., Nezhadahmadi, A., \& Osman, M. (2014). Genetic analysis of $\mathrm{F} 1$ hybrids derived from aromatic (Exotic) $\times$ Aromatic (Malaysian) rice crosses and their callus induction performance for haploid production. Indian Journal of Science and Technology, 7(11), 1852-1860.

Góralski, G., Rozier, F., Matthys-Rochon, E., \& Przywara, L. (2005). Cytological features of various microspore derivatives appearing during culture of isolated maize microspores. Acta Biologica Cracoviensia Series Botanica, 47(1), 75-83.

Gueye, T., \& Ndir, K. N. (2010). In vitro production of double haploid plants from two rice species (oryza sativa L. and oryza glaberrima steudt.) for the rapid development of new breeding material. Scientific Research and Essays, 5(7), 709-713.

Indrianto, A., Barinova, I., Touraev, A., \& Heberle-Bors, E. (2001). Tracking individual wheat microspores in vitro: Identification of embryogenic microspores and body axis formation in the embryo. Planta, 212(2), 163-174. doi:10.1007/s004250000375

Joosen, R., Cordewener, J., Supena, E. D. J., Vorst, O., Lammers, M., Maliepaard, C., ... Boutilier, K. (2007). Combined transcriptome and proteome analysis identifies pathways and markers associated with the establishment of rapeseed microsporederived embryo development. Plant Physiology, 144(1), 155172. doi:10.1104/pp.107.098723

Kyo, M., \& Harada, H. (1986). Control of the developmental pathway of tobacco pollen in vitro. Planta, 168(4), 427-432. doi:10.1007/BF00392260

Malik, M. R., Wang, F., Dirpaul, J. M., Zhou, N., Polowick, P. L., Ferrie, A. M. R., \& Krochko, J. E. (2007). Transcript profiling and identification of molecular markers for early microspore embryogenesis in Brassica napus. Plant Physiology, 144(1), 134-154. doi:10.1104/pp.106.092932

Maraschin, S. F., De Priester, W., Spaink, H. P., \& Wang, M. (2005). Androgenic switch: An example of plant embryogenesis from the male gametophyte perspective. Journal of Experimental Botany, 56(417), 1711-1726. doi:10.1093/jxb/eri190

Obert, B., Szabó, L., Mitykó, J., Pret’ová, A., \& Barnabás, B. (2005). Morphological events in cultures of mechanically isolated maize microspores. In Vitro Cellular and Developmental Biology . Plant, 41(6), 775-782. doi:10.1079/IVP2005701

Pauls, K. P., Chan, J., Woronuk, G., Schulze, D., \& Brazolot, J. (2006). When microspores decide to become embryos - Cellular and molecular changes. Canadian Journal of Botany, 84(4), 668678. doi:10.1139/B06-064

Premvaranon, P., Vearasilp, S., Thanapornpoonpong, S. nguansak, Karladee, D., \& Gorinstein, S. (2011). In vitro studies to produce double haploid in Indica hybrid rice. Biologia, 66(6), 1074-1081. doi:10.2478/s11756-011-0129-8

Sanchez-Diaz, R. A., A. M. Catillo, M. P. V. (2013). Microspore embryogenesis in wheat: new marker genes for early, middle and late stages of embryo development. Plant Reprod, 26, $287-$ 296. doi:10.1007/s00497-013-0225-8

Satpute, G. K., Long, H., \& Testillano, P. S. (2005). Cell ar chi tec ture dur ing gametophytic and embryogenic microspore de vel op ment in Bras sica napus L ., 27(4), 665-674.

Seguí-Simarro, J. M., \& Nuez, F. (2008). How microspores transform into haploid embryos: Changes associated with embryogenesis induction and microspore-derived embryogenesis. Physiologia Plantarum, 134(1), 1-12. doi:10.1111/j.1399-3054.2008.01113.x

Seifert, F., Bössow, S., Kumlehn, J., Gnad, H., \& Scholten, S. (2016). Analysis of wheat microspore embryogenesis induction by transcriptome and small RNA sequencing using the highly responsive cultivar "Svilena." BMC Plant Biology, 16(1), 1-16. doi:10.1186/s12870-016-0782-8

Touraev, A., Vicente, O., \& Heberle-Bors, E. (1997). Initiation of microspore embryogenesis by stress. Trends in Plant Science, 2(8), 297-302. doi:10.1016/S1360-1385(97)01083-2

Zhang, D., Luo, X., \& Zhu, L. (2011). Cytological analysis and genetic control of rice anther development. Journal of Genetics and Genomics, 38(9), 379-390. doi:10.1016/j.jgg.2011.08.001 